\title{
Contraceptive awareness, and practices among rural women in Lucknow
}

\author{
Asma Nigar \\ Associate Professor, Dept. of Obstetrics and Gynecology, Integral Institute of Medical Sciences and Research, Lucknow, Uttar \\ Pradesh, India \\ *Corresponding Author: Asma Nigar \\ Email: drasmanigar@gmail.com
}

Received: $22^{\text {nd }}$ May, 2018

Accepted: $10^{\text {th }}$ September, 2018

\begin{abstract}
Objective: This cross sectional observational study was done to asses awareness regarding family planning methods and the practice of contraceptives among rural women in Lucknow.

Materials and Methods: Five hundred women between the ages of 15-45 years, living with their husbands and coming from rural area, attending gynecology OPD of integral institute of medical sciences and research, Dasauli, Lucknow were included in this study. Women who were pregnant, had a child younger than 2 years, or had any medical disorder were excluded. Their knowledge, source of knowledge and practice of contraceptives were evaluated with the help of a predesigned questionnaire. The other variables used were the age of women, parity, religion and educational status. Results were expressed as percentages.

Results: Out of 500 interviewed majority of women (49.2\%) were between 22-25 years of age. $61 \%$ were illiterate belonging to low socioeconomic status, $63.3 \%$ belonged to Hindu religion. In the present study, it was observed that, $94.4 \%$ had some knowledge about family planning methods, and almost all (94.4\%) of them were aware about $\mathrm{Cu} \mathrm{T}$ and oral pills. The media and social circle were provided information of contraceptives in $46.6 \%$ women. Regarding the usage of contraceptive methods, $41.2 \%$ of the respondents were using some sort of contraception. Barrier method (condoms) was in practice by $26.8 \%$, pills in 5.6\% $\mathrm{Cu} \mathrm{T}$ users were $3.2 \%$ and $1.2 \%$ were using DMPA for contraception. $4.4 \%$ of women had already undergone tubal ligation. It was noted that awareness about pills and Copper was good, but their practices were very low. There were multiple reasons for non use like fear of side effects, no support from the husbands, low fertility, inhibition to ask about the contraceptives.

Conclusion: There is need for strong motivation of couples through media and health personnel to achieve effective use of contraceptives, specially for $\mathrm{Cu} \mathrm{T}$ and oral pills.
\end{abstract}

Keywords: Contraception, Awareness, Practice.

\section{Introduction}

The most important problem that India is facing now is the uncontrolled growth of population. In spite of availability of a wide range of contraceptives, mass media campaigns and IEC programs for family planning, population control still remains a distant dream to achieve. Though the permanent methods have been successful in our country the spacing methods lag behind and unwanted unplanned pregnancies continue to be high. India was one of the pioneers to start family welfare program which was started in 1950s. In spite of that, it is the second most populous country in the world and the rate of population growth is a matter of concern for its growth and development. There are many social factors, taboos, myths and ignorance which is responsible for underutilization of contraceptive services. This leads to many unwanted pregnancies causing maternal morbidity and mortality. Use of effective contraception is one of primary strategy to prevent maternal mortality \& morbidity by decreasing unwanted pregnancies \& abortions. Understanding the contraceptive needs \& practices of particular community is important to help policy makers design various policies. The present study was undertaken in patients attending gynecology OPD to know the awareness level and practices regarding contraceptive usage.

\section{Materials and Methods}

The present study is a cross sectional observational study, conducted in the department of obstetrics and gynecology, at Integral Institute of Medical Sciences and Research, a tertiary care hospital in rural area mainly catering health services to rural population. Five hundred women between the age of 15-45 years, living with their husbands and coming from rural area were interviewed. Women who were pregnant, had a child younger than 2 years, or had any medical disorder were excluded. Their awareness about various contraceptive methods and practices were evaluated with the help of a predesigned questionnaire. The other variables used were the age of women, parity, religion and educational status females and their husbands. Results were expressed as percentages.

\section{Results}

Table 1 shows that majority of women were between $22-25$ years of age (49.2\%). $80 \%$ females had parity more than 2 .

$63.3 \%$ women belonged to Hindu religion. 
Table 1: Demographic characteristic of the study group

\begin{tabular}{|l|c|c|}
\hline Characteristic & $\begin{array}{c}\text { No. of females }(\mathbf{n}= \\
\mathbf{5 0 0})\end{array}$ & $\mathbf{\%}$ \\
\hline Age in years & & \\
\hline $18-21$ & 23 & 4.6 \\
$22-25$ & 246 & 49.2 \\
$26-30$ & 160 & 32 \\
$31-35$ & 50 & 10 \\
35 & 21 & 4.2 \\
\hline Religion & & \\
\hline Hindu & 316 & 63.3 \\
Muslim & 184 & 36.7 \\
\hline Parity & & \\
\hline 0 & 44 & 8.8 \\
1 & 56 & 11.2 \\
2 & 128 & 25.6 \\
3 & 89 & 17.8 \\
4 & 183 & 36.6 \\
\hline
\end{tabular}

Table 2 shows educational status of study population and husbands educational status. Among them, $61 \%$ were illiterate, and among literates, $23.2 \%$ had primary education, $11.2 \%$ were high school passed, $4.4 \%$ were intermediate pass and $0.2 \%$ were graduates.

This table also shows literacy status of husbands. $26.6 \%$ were illiterate. $5.6 \%$ had primary schooling, $31 \%$ had mid and high school education, $22.4 \%$ were educated till intermediate, $14.8 \%$ were graduates and above.

Table 2: Educational status in study group

\begin{tabular}{|l|c|c|}
\hline \multicolumn{1}{|c|}{ Literacy status } & Number & \% \\
\hline Literacy status of wife & & \\
\hline illiterate & 305 & 61 \\
primary & 116 & 23.2 \\
High school & 56 & 11.2 \\
intermediate & 22 & 4.4 \\
graduate & 1 & .2 \\
\hline Literacy status of husband & & \\
\hline illiterate & 133 & 26.6 \\
primary & 28 & 5.6 \\
Mid and high school & 155 & 31 \\
intermediate & 112 & 22.4 \\
graduate & 35 & 7 \\
Above graduate & 39 & 7.8 \\
\hline
\end{tabular}

Table 3 shows awareness and practices regarding various contraceptive methods. $94.4 \%$ had knowledge about at least one modern method of contraception. All of them (94.4\%) were aware of copper $\mathrm{T}$ and pills, $87.8 \%$ were aware of condoms, and $73.3 \%$ were aware of inject able contraceptives. $83.3 \%$ were aware of permanent sterilization.

Regarding practices, it was observed that $41.2 \%$ were practicing modern method of contraception. Most commonly used method was condom in $26.8 \%, 5.6 \%$ were practicing pills, $3.2 \%$ were using $\mathrm{Cu}$ T, and $1.2 \%$ were using injectables. $4.4 \%$ females had underwent ligation.

Table 3: Various sources regarding knowledge of contraceptives

\begin{tabular}{|l|c|c|}
\hline Source & $\begin{array}{c}\text { No. of females } \\
(\mathbf{n = 4 7 2})\end{array}$ & $\mathbf{\%}$ \\
\hline Media-TV and radio & 220 & 46.6 \\
ANM/health worker & 112 & 23.7 \\
Neighbor and friends & 140 & 29.6 \\
\hline
\end{tabular}

Table 4 shows sources of knowledge about contraceptives. Most common source was found to be media and $\mathrm{T}$ V (46.6\%), 29.6\% heard about contraceptive methods from neighbors and friends and $23.7 \%$ had it through ANM and health workers.

Table 4: Awareness and practices regarding various contraceptive method

\begin{tabular}{|l|c|c|}
\hline \multicolumn{1}{|c|}{ Method } & Awareness & Practice \\
\hline Permanent & $41683.3 \%$ & $224.4 \%$ \\
\hline Temporary & & \\
\hline Cu T & $47294.4 \%$ & 163.2 \\
Pills & $47294.4 \%$ & 285.6 \\
condom & $43687.8 \%$ & 13426.8 \\
Injectables & $36773.3 \%$ & 61.2 \\
\hline
\end{tabular}

Table 5 shows various reasons for non use of contraception. In $20 \%$ females, husbands were not supportive to use it, $32 \%$ had fear of side effects, $9.2 \%$ said that they naturally didn't have pregnancies, $5 \%$ had inhibition to ask about it, $5.6 \%$ were not aware of it, and $3.2 \%$ were desirous of having son.

Table 5: Various reasons for nonuse of contraceptive methods

\begin{tabular}{|l|c|c|}
\hline \multicolumn{1}{|c|}{ Reason } & $\begin{array}{c}\text { No. of females } \\
\text { (n=294) }\end{array}$ & \% \\
\hline Not aware & 28 & 5.6 \\
Not favoured by husband & 100 & 20 \\
Fear of side effects & 160 & 32 \\
Desire of son & 16 & 3.2 \\
Inhibition to ask & 25 & 5 \\
Naturally doesn't have & 46 & 9.2 \\
pregnancies & & \\
\hline
\end{tabular}

\section{Discussion}

Current study included 500 females of reproductive age group from rural area of Lucknow. In this study maximum number of women (49.2\%) were in between $22-25 \mathrm{yrs}$ of age which is the peak period of fertility during which most pregnancies occur.

$61 \%$ females were illiterate. Educational status of husbands showed that $73.4 \%$ were literate and among them maximum (53.4\%) were high school and intermediate pass. 
In our study we found that awareness of at least one method of contraception in women of reproductive age group was wide but contraceptive practice was very low, specially for $\mathrm{Cu} \mathrm{T}$ and pills. Knowledge of at least one method of contraception was present in $94.4 \%$ women. The findings are similar to prevalence of knowledge being $97.7 \%$ in women as reported by NFHS-III. ${ }^{1}$

A similar level of awareness was reported by Sunita Ghike et al in their study on 1000 patients from rural area. Knowledge about at least one method of contraception was present in all women $(100 \%){ }^{2}$

It was found that maximum females $(94.4 \%)$, in this study were found to be aware of $\mathrm{Cu} \mathrm{T}$ and oral pills, followed by condom (87.8\%), and injectables (73.3\%). Awareness about ligation was seen in $83.3 \%$.

Sunita Ghike et al showed maximum awareness about $\mathrm{Cu} \mathrm{T}$ in $67.5 \%$ females, condom in $57.9 \%$, pills in $34 \%$ and injectables in $14.9 \%{ }^{2}$

Varying results about knowledge of contraceptive methods have been shown in other previous studies conducted in rural population.

In a study of rural Lucknow it showed that, $1.2 \%$ rural women were unaware of any method of family planning. $47.2 \%$ of women did not use any family planning method in past. ${ }^{3}$

In study by Sharma et al, 70\% women were aware of at least one method of contraception though only $30 \%$ had knowledge about the correct use. ${ }^{4}$

Another study, conducted in north Indian rural population showed 55\% awareness level about at least one method of contraception. ${ }^{5}$

In one study from rural area of Tamil Nadu, it was seen that all the women knew about at least one method of contraception $(100 \%)$. al. ${ }^{6}$

Awareness level was $87 \%$ in a study by Pegu B et

On assessing the knowledge, Kushwaha et al found that $58 \%$ of the women were aware of at least one of the available family planning. ${ }^{7}$

According to the National Family Health Survey 3 which found a nearly universal knowledge about contraception but contrary to this the usage was only $56 \%$. However this survey had included all women from 15-45 years (rural as well as urban). ${ }^{8}$

Regarding practices of modern contraceptives, usage was seen in $41.2 \%$ female in our study. Most common method practiced was condom in $26.8 \%$, followed by pills in $5.6 \%, \mathrm{Cu} \mathrm{T}$ in $3.2 \%$ and injectables was seen in only $1.2 \% .4 .4 \%$ had already undergone ligation.

Similar low practice of pills were reported by several other studies in India. ${ }^{7,9}$

In a study conducted in rural Lucknow, the most commonly used method was condom (34\%). ${ }^{3}$ Sunita et al showed that most common method practiced was $\mathrm{Cu}$ $\mathrm{T}(22.7 \%)$ that was much higher than in our study. ${ }^{2}$
Pegu B et $\mathrm{al}^{6}$ showed barrier method as the most commonly used method as was seen in our study also.

In a study conducted in rural area of Moradabad, practice of contraceptive method was found to be $41 \% .^{10}$

Major source of knowledge was media (46.6\%) followed by social circle (29.6\%) and health workers (23.7\%). Kokane AM et al also reported that Social media $(74.5 \%)$ and health care providers $(61.1 \%)$ were the most common source of information. ${ }^{11}$

This study shows that there are multiple factors in our society that discourage use of contraceptives. Various reasons for not using any method of contraceptives showed that $58.8 \%$ were not using any method of contraception. Among them, most common were the fear of side effects (32\%), and not favoured by husband (20\%). 9.2\% women thought that they naturally don't have pregnancy because of low fertility. Other factors were unawareness $(5.6 \%)$, inhibition to ask $(5 \%)$, and desire for son $(3.2 \%)$.

In a study by Sharma $\mathrm{j}$ et al it was shown that even after receiving adequate knowledge only $28.2 \%$ were willing to adopt a method of contraception. ${ }^{4} 65.8 \%$ were not willing to adopt a method. Fear of side effects was perceived by $26 \%$ of those having negative attitude for modern contraception. In $16 \%$, the want of family/ husband approval was a factor and $23 \%$ thought that it is not necessary as they have a low risk of pregnancy. The fear of side effects has been a recurring factor reported in many studies. ${ }^{12,13}$

It is evident from this study that inspite of high awareness, practice of modern contraceptives is very low in our population.

Constant motivation by healthcare workers, alleviating fear of side effects and myths, and councelling of husbands are very important to improve the contraceptive use among population.

\section{Conclusion}

Thus we conclude that in our study population the high level of awareness needs to be translated to knowledge by proper and detailed counseling. The fear of side effects of the contraceptive methods specially for $\mathrm{Cu} \mathrm{T}$ and oral pills, and negative attitude of husbands and their approval turned out to be the most important factors affecting their use.

Proper and detailed counseling about the methods and doing away with the myths and involving husbands in these sessions would be important strategies to improve the effective use of spacing contraception in eligible couples.

Funding: No funding sources

Conflict of Interest: None declared 


\section{References}

1. National Family Health Survey (NFHS-3), 2005-06, India. International Institute for Population Sciences, Mumbai.

2. Sunita Ghike, Sulbha Joshi, A Bhalerao, A Kawthalkar awareness and contraception practices among women- an Indian rural experience. South Asian Federation of Obstetrics and Gynecology. 2010;2(1):19-21.

3. Vasundhara Sharma, Uday Mohan, Vinita Das, and Shally Awasthi Sharma J. Socio Demographic Determinants and Knowledge, Attitude, Practice: Survey of Family Planning. Int J Reprod Contracept Obstet Gynecol. 2015;4(3):750-754.

4. Harpreet Kaur. Knowledge, attitude, practices and behavior of women towards contraceptive use- a study of women attending north Indian rural hospital. Indian Journal of Obstetrics and Gynecology Research. 2014;1(1):25-30.

5. Pegu B, Gaur BP Singh, Sharma N, Singh AS. Int J Reprod Contracept Obstet Gynecol. 2014;3(2):385-388.

6. Kushwaha B. Int J Reprod Contracept Obstet Gynecol. 2015;4(2):329-333.

7. National Family Health Survey (FNFHS-III), India. International Institute for Population Sciences (IIPS) and Macro International. 20071:192-222. Available from: http://www.nfhsindia.org

8. Takkar N, Goel P, Saha P K, Dua D. Contraceptive practices and awareness of emergency contraception in educated working women. Indian J Med Sci. 2005;59(4):143-9.

9. Sandeep Rankawat, N V Nuninarayannappa, Ramnivas Chaudhary. Knowledge and practice of contraceptive methods in rural eligible couple, Moradabad. Journal of Harmonized Research in Medical and Health Sci. 2016;3(4):217-222.

10. Kokane AM, Palanivel C, Mahajan PB, Nair K, Bipin BB. Assessment of knowledge and practice of contraception among antenatal cases attending ANC Clinic Indian J Maternal Child Health. 2011;13(4):2-8.

11. Alaknanda, Bhattacharyya AK, Das I. Sch J App Med Sci. 2015;3(3):1505-8.

12. Umoh AV, Abah AG. Contraception awareness and practice among antenatal attendees in Uyo, Nigeria. Pan African Med J. 2011;10:53.

How to cite this article: Nigar A. Contraceptive awareness, and practices among rural women in Lucknow. Indian J Obstet Gynecol Res. 2018;5(4):454-457. 